\title{
CYP1A1 genotypes and haplotypes and risk of oral cancer: A case-control study in South Indians
}

\author{
${\text { Lakshmi Balaji }{ }^{1} \text {, Krishna Balaji Singh }}^{2}$ and Lakkakula V.K.S. Bhaskar ${ }^{3}$ \\ ${ }^{1}$ Department of Endodontics, Sri Ramachandra Dental College and Hospital, \\ Sri Ramachandra University, Chennai, India. \\ ${ }^{2}$ Department of General Surgery, Sri Ramachandra Medical College and Hospital, \\ Sri Ramachandra University, Chennai, India. \\ ${ }^{3}$ Department of Biomedical Sciences, Sri Ramachandra University, Chennai, India.
}

\begin{abstract}
The CYP1A1 gene encodes for the enzyme, aryl hydrocarbon hydroxylase, which is involved in the biotransformation of various aromatic tobacco precarcinogens. In the present study, the association between CYP1A1 gene polymorphisms (IVS1-728G > A, Thr461Asn and lle462Val), and the risk of oral cancer, was examined among 157 patients with oral cancer and 132 age-matched controls, in a south Indian population. The strength of the association between CYP1A1 variants and oral cancer was estimated by logistic regression. It was found that Thr461Asn was not polymorphic. Both IVS1-728G > A and Ile462Val frequencies were consistent with Hardy-Weinberg equilibrium in the control group. There were no significant differences in genotype or haplotype frequencies between controls and cases with oral cancer. Hence, CYP1A1 SNPs can be considered as not being associated with oral cancer at either the genotype or haplotype levels in the population studied.
\end{abstract}

Key words: CYP1A1, haplotypes, allele, oral cancer.

Received: September 7, 2011; Accepted: December 16, 2011.

\section{Introduction}

Oral squamous cell carcinoma (OSCC) is a significant global health problem with increasing incidence and mortality rates. Annually, approximately 500,000 patients are diagnosed with oral cancer worldwide (Parkin et al., 2005). Smoking is by far the major risk factor for developing oral cancer. The use of alcohol and smoking further increases the risk of oral cancer, along with cancer of the larynx and esophagus. About 300 carcinogens in tobacco smoke or components are known to leach from smokeless tobacco into saliva (International Agency for Research on Cancer, 1987). The most outstanding are the aromatic hydrocarbon benzpyrene, and the tobacco-specific nitrosamines (TSNs), nitroso-nor-nicotine (NNN), nitrosopyrrollidine (NPYR), nitrosodimethylamine (NDMA), and 4-(methylnitrosamino)-1-(3-pyridyl)- 1-butanone (NNK). Their metabolism usually involves oxygenation by $\mathrm{p} 450$ enzymes in cytochromes, followed by conjugation with the enzyme glutathione S transferase (GST) (Nakajima et al., 1995). The CYP1A1 gene encodes for the enzyme aryl hy-

Send correspondence to L.V.K.S. Bhaskar. Department of Biomedical Sciences, Sri Ramachandra University, No.1 Ramachandra Nagar, 600116 Porur, Chennai, India. E-mail: Ivksbhaskar@gmail.com. drocarbon hydroxylase, involved in the biotransformation of various aromatic tobacco precarcinogens (Nebert, 1991).

The CYP1A1 gene has seven exons and is located on chromosome 15q22-24 (Hildebrand et al., 1985). It is well established that both CYP1A1 expression and activity are inducible by PAHs through the activation of an aryl hydrocarbon receptor, a ligand activated transcription factor (Whitlock, 1999; Ma and Lu, 2007). Certain polymorphic variants of CYP1A1 genes, besides causing enhanced enzyme activity, are also known to play a major role in the pathogenesis of several cancers (Singh et al., 2007; Wright et al., 2010; Kristiansen et al., 2011). These CYP1A1 polymorphisms have been extensively studied with regard to oral cancer risk. Although some studies report increased risk in the presence of some of the mutations (Park et al., 1997; Oude Ophuis et al., 1998; Xie et al., 2004), there are many contradictory results apparently due to ethnic differences (Leichsenring et al., 2006; Chatterjee et al., 2009), whereby the perception of inconsistency in findings (Zhuo et al., 2009). Since one of the major risk factors for oral cancer is tobacco use, we hypothesized that polymorphisms in genes coding for tobacco carcinogen-metabolizing enzymes may play a role in oral cancer susceptibility. Therefore, a case-control study was undertaken to extend investigations on specific genetic risk factors in a south Indian 
population, hence the evaluation of the effect of CYP1A1 gene polymorphisms in developing this risk.

\section{Materials and Methods}

\section{Subjects}

Three $\mathrm{ml}$ blood samples were obtained from 157 oral-cancer patients receiving care at the Kanchipuram cancer hospital. The mean age was $55.07 \pm 10.59$ years, and included $54.8 \%$ men. Diagnosis of the oral cancer as squamous cell carcinoma was confirmed histopathologically. The anonymous donors, with no personal history of cancer of any organ, and which formed the control group of subjects, were recruited from the Sri Ramachandra Medical College. On routine questioning and examination, all the 132 control donors, with a mean age of $53.08 \pm 10.72$ years and including $34.8 \%$ men, appeared healthy. For cases and controls, information regarding age, gender, occupation and details about duration, frequency, nature of the tobacco habit (smoking or smokeless), and alcohol consumption was noted through a detailed questionnaire. 54 (34.4\%) of the oral-cancer patients were habitual smokers, whereas only 23 individuals (17.4\%) were so in the control group. Prior to the study, all the patient-participants gave informed written-consent. The study was approved by the Ethics Committee of Sri Ramachandra University, Chennai, under the guidelines of the Ministry of Education, Culture, Science and Technology.

\section{Genotyping}

Genomic DNA was extracted from all the participants, according to a published protocol (Thangaraj et al., 2002). Three SNPs of the CYP1A1 gene rs4646421 (Intron 1), rs1799814 (Thr461Asn) and rs1048943 (Ile462Val) were genotyped. The primers and probes for all the SNPs (Table 1) used in this study were purchased from Applied Biosystems (Foster City, CA, USA). Each reaction contained $2.5 \mu \mathrm{L}$ of TaqMan Universal PCR Master Mix, $0.125 \mu \mathrm{L}$ of TaqMan SNP Genotyping Assay, $1.375 \mu \mathrm{L}$ of distilled water and $1 \mu \mathrm{L}$ of DNA $(10 \mathrm{ng} / \mu \mathrm{L})$, thus reaching a final volume of $5 \mu \mathrm{L}$. At least two non-template controls without DNA were included in each of the 384 well-plates. These plates also contained a positive control for wild-type and variant genotypes. Before DNA analysis, a pilot test was run to confirm assay-accuracy. After successful pilot testing, sample analysis was carried out with 384-well optical reaction microplates (Applied Biosystem). Fluorescence was measured with an Applied Biosystems 7900HT Fast Real-Time PCR System, and analyzed with its System SDS 2.3 software version.

\section{Statistical analysis}

Allele frequencies were determined by direct gene counting. Genotype distribution of each site per sample was evaluated for Hardy-Weinberg equilibrium by using a Monte Carlo permutation test implemented in the HWSIM program (Cubells et al., 1997). Besides computing expected genotype distribution according to HardyWeinberg proportions, HWSIM also tests for agreement between observed and expected distribution, through the usual chi-square test. In order to estimate the strength of association between CYP1A1 variant alleles and smoking status, their interaction in causing oral cancer was assayed through logistic regression analysis. Genotype indicator variables were created by using the wild-type genotype as the reference category in regression models. As the homozygous Ile $462 \mathrm{Val}$ variant trait is infrequent in the study subjects, cancer risk associated with the combined hetero-

Table 1 - Primers and probes used for genotyping CYP1Al gene polymorphisms.

\begin{tabular}{|c|c|c|}
\hline Gene/Polymorphism & Primers/Probe & Sequence \\
\hline \multirow[t]{4}{*}{ rs4646421 } & Forward & CCTTCATTGATCTGACCACTCTTCA \\
\hline & Reverse & ACTCAGACTCCTTAGGGACACTTC \\
\hline & Probe $1(\mathrm{VIC})^{1}$ & 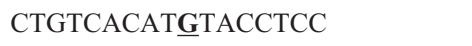 \\
\hline & Probe 2 (FAM) & CTGTCACAT $\underline{A} T A C C T C C$ \\
\hline \multirow[t]{4}{*}{ rs1799814 (Thr461Asn; m4) } & Forward & GGGCAAGCGGAAGTGT \\
\hline & Reverse & GAGAAAGACCTCCCAGCGG \\
\hline & Probe 1 (VIC) & TCGGTGAGA $\underline{\text { ACATTGC }}$ \\
\hline & Probe 2 (FAM) & CGGTGAGA $\underline{C}$ CATTGC \\
\hline \multirow[t]{4}{*}{ rs1048943(Ile462Val; m2) } & Forward & GCAAGCGGAAGTGTATCGG \\
\hline & Reverse & AAGAGAAAGACCTCCCAGC \\
\hline & Probe 1 (VIC) & TGAGACC므TTGCCC \\
\hline & Probe 2 (FAM) & TGAGACCGTTGCCC \\
\hline
\end{tabular}

${ }^{1}$ Probes corresponding to different alleles were labeled with VIC and FAM fluorescent dyes (Applied Biosystems).

${ }^{2}$ Polymorphic bases are underlined. 
zygous and homozygous variants in our analysis (wildtype individuals versus 'any variant allele') was examined. The statistical package SPSS 14.0 was used for computing percentages, odds ratios (OR) with a 95\% confidence interval and chi square tests. Linkage disequilibrium (LD) values of $D^{\prime}$ and $r^{2}$ were estimated using HaploView 3.12 (Barrett et al., 2005). The THESIAS program was also used for haplotype-phenotype analysis (Tregouet and Garelle, 2007).

\section{Results}

The difference between the mean ages of control and oral cancer subjects $(53.08 \pm 10.72$ vs. $55.07 \pm 10.59$; $\mathrm{p}=0.113$ ) was insignificant. On the other hand, the percentage of men included was $54.8 \%$ and $34.8 \%$ in oral cancer and control groups, respectively. 54 (34.4\%) of oral cancer patients of the study admitted to habitual smoking, whereas in the control group only $23(17.4 \%)$ subjects did so. The distribution of smokers was significantly different between cases and controls $(\mathrm{p}=0.001)$ with OR $(\mathrm{CI}) 2.485$ (1.375-4.512). According to genotype analysis, rs 1799814 was not polymorphic. Minor allele frequencies of the two polymorphisms in the control group was $35.2 \%$ and $13.6 \%$ for IVS1-728G > A and Ile462 Val, respectively. For both, frequencies were consistent with Hardy-Weinberg equilibrium in the control group (Table 2). There were no significant differences in genotype or allele frequencies of two SNPs (IVS1-728G $>$ A and Ile462Val) between controls and cases with oral cancer (Table 2). Following stratification of the study subjects according to smoking status (non-smokers and smokers), genotype groups of both SNPS proved not to be significantly associated to oral cancer risk. In non-smokers, observed ORs (CI) for subjects carrying IVS1-728G $>$ A, and Ile462Val polymorphisms were $1.529(0.844-2.772)$ and $0.966(0.483-1.930)$, respectively. As to smokers, OR (CI) values for the same genotype groups were $1.558(0.520-4.689)$ and 0.992 (0.289-3.491), respectively. Furthermore, stratified analysis by smoking status provided no support to either interaction or confounding, thereby indicating observed association to be the most precise and unbiased (Table 3). IVS1-728G $>$ A and Ile462Val were in weak linkage disequilibrium (LD), $\mathrm{D}^{\prime}=0.678 ; \mathrm{r}^{2}=0.116$. According to haplotype phenotype association analysis, there was no evidence of association (Table 4).

\section{Discussion}

It is well known that the induction of CYP1A1 plays a major role in the development of oral cancer and other smoking-related respiratory-tract cancers (Rendic and Guengerich, 2010). The PAHs present in tobacco smoke activate CYP1A1 gene transcription (Omiecinski et al., 1990), whereas in turn, CYP1A1 enzymes convert PAHs into active carcinogens (Hecht et al., 1993). There are contradictory reports on the role of $C Y P 1 A 1$ variants in altering the levels of gene expression or mRNA stability. Ile462Val polymorphism revealed higher levels of induced or basal CYP1A1 mRNA, with an increase in Val variants, whereas in purified Escherichia coli, there was no difference in benzo $[a]$ pyrene metabolism in Ile and Val variants (Crofts et al., 1994; Zhang et al., 1996). In the present study, investigation of IVS1-728G > A (rs4646421), Thr461Asn (rs1799814) and Ile462Val (rs1048943) in the CYP1A1 gene revealed only IVS1-728G > A and Ile462Val to be polymorphic in this south Indian population. Although smoking was established as a risk factor in the present

Table 2 - Distribution of genotypes and the relationship between polymorphisms of the CYP1A1 gene and the risk of oral cancer.

\begin{tabular}{lcccc}
\hline Genotype & Control & Oral cancer & OR (95\% CI $)$ & p value \\
\hline GG & $59(44.70 \%)$ & IVS1-728G > A (rs4646421) & Reference \\
GA & $53(40.15 \%)$ & $55(35.03 \%)$ & $1.619(0.947-2.773)$ & 0.073 \\
AA & $20(15.15 \%)$ & $80(50.96 \%)$ & $1.180(0.548-2.544)$ & 0.719 \\
GA+AA & $73(55.30 \%)$ & $22(14.01 \%)$ & $1.499(0.907-2.479)$ & 1.160 \\
MAF & 35.2 & $102(64.97)$ & & 0.772 \\
HWE p & 0.167 & 39.5 & $1.101(0.596-2.036)$ & 0.476 \\
& & 0.407 & $0.505(0.093-2.50)$ & 1.000 \\
AA & $101(76.52 \%)$ & $120(76.43 \%)$ & $1.005(0.562-1.797)$ & \\
AG & $26(19.70 \%)$ & $34(21.66 \%)$ & \\
GG & $5(3.78 \%)$ & $3(1.91 \%)$ & & \\
AG+GG & $31(23.48 \%)$ & $37(23.57 \%)$ & 12.7 & \\
MAF & 13.6 & 0.745 & & \\
HWE p & 0.060 & Reference & \\
\hline
\end{tabular}

MAF: Minor allele frequency; OR: odds ratio; HWE p: Hardy-Weinberg equilibrium p value. 
Table 3 - Joint effects between genotypes and smoking status.

\begin{tabular}{|c|c|c|c|c|c|c|c|}
\hline Genotype & Smoking & Cases n $(\%)$ & Control n (\%) & $\begin{array}{l}\text { Strata specific } \\
\text { OR }(95 \% \mathrm{CI})\end{array}$ & $\begin{array}{c}\text { Strata specific } \\
\text { p value }\end{array}$ & $\begin{array}{l}\text { Interaction OR } \\
(95 \% \mathrm{CI})\end{array}$ & $\mathrm{p}_{\text {-interaction }}$ \\
\hline \multicolumn{8}{|l|}{ Rs4646421 } \\
\hline GG & No & $35(22.3)$ & $48(36.4)$ & Reference & & & \\
\hline $\mathrm{GA}+\mathrm{AA}$ & No & $68(43.3)$ & $61(46.2)$ & $1.53(0.84-2.77)$ & 0.134 & & \\
\hline GG & Yes & $20(12.7)$ & $11(8.3)$ & Reference & & & \\
\hline $\mathrm{GA}+\mathrm{AA}$ & Yes & 34 (27.7) & $12(9.1)$ & $1.56(0.52-4.69)$ & 0.377 & $1.54(0.92-2.57)$ & 0.107 \\
\hline \multicolumn{8}{|l|}{ rs1048943 } \\
\hline AA & No & $80(51.0)$ & $84(63.6)$ & Reference & & & \\
\hline $\mathrm{AG}+\mathrm{GG}$ & No & $23(14.6)$ & $25(18.9)$ & $0.97(0.48-1.93)$ & 0.916 & & \\
\hline AA & Yes & $40(25.5)$ & $17(12.9)$ & Reference & & & \\
\hline $\mathrm{AG}+\mathrm{GG}$ & Yes & $14(8.9)$ & $6(4.5)$ & $0.99(0.29-3.70)$ & 0.988 & $0.97(0.54-1.76)$ & 0.965 \\
\hline
\end{tabular}

Abbreviations: CI, confidence interval; OR, odds ratio.

Table 4 - CYP1A1 gene haplotypes and oral cancer.

\begin{tabular}{lcccc}
\hline rs4646421 and rs1048943 & & & \\
\hline Haplotype & Control & Case & OR $(95 \%$ CI $)$ & p value \\
\hline GA & 0.613 & 0.585 & Reference & \\
GG & 0.034 & 0.02 & $0.511(0.142-1.842)$ & 0.305 \\
AA & 0.25 & 0.287 & $1.185(0.794-1.767)$ & 0.407 \\
AG & 0.102 & 0.108 & $1.131(0.665-1.923)$ & 0.651 \\
\hline
\end{tabular}

study, IVS1-728G > A and Ile462Val polymorphisms of the CYP1A1 gene were not associated with the risk of oral cancer. Furthermore, CYP1A1 SNPs could not even be associated with oral cancer at either the genotype or haplotype levels.

Although Thr461Asn (m4), specific for Caucasians and with a frequency ranging from 3 to $6 \%$, has also been related to greater enzyme catalytic efficiency (Schwarz et al., 2001), none of the subjects in our sample carried this variant. The famous and well studied Ile462Val (m2) variant in CYP1 A1, present in both Caucasians (7\%) and Asians $(35 \%)$, is mostly detected in linkage disequilibrium with m1 (MspI site) (Georgiadis et al., 2005). A study from North India revealed $51 \%$ and $17 \%$ of the CYP1A1 m2 allele (462Val carriers), respectively, in oral cancer and controls, thus associated with increased risk (Sreelekha et al., 2001). In another study, also of a north Indian population, the frequencies of genotypes were similar in patient and control groups, with no indication of any significant association (Sikdar et al., 2003). An analysis of Caucasian oralcancer patients revealed almost identical heterozygous genotype distribution between cases and controls $(6.5 \%$ oral cancer, $4.3 \%$ controls), with no association between $\mathrm{m} 2$ and oral cancer (Hahn et al., 2002). The Ile462Val heterozygous genotype is significantly associated with the earlier age of onset of OSCC than in the wild homozygous geno- type (Kao et al., 2002). Two independent case-control studies from Puerto Rico and south Brazil, revealed that genotypes of the CYP1A1 (462Val) variant were not associated with oral-cancer risk (Xie et al., 2004; Leichsenring et al., 2006). Chilean individuals carrying a $\mathrm{T}$ to $\mathrm{C}$ substitution at the 3' untranslated region $(C Y P 1 A 1 * 2 \mathrm{~A} / \mathrm{m} 1$ allele/ rs4646903), are reported to be more susceptible to oral cancer induced by environmental tobacco smoking (Cordero et al., 2010).

Although no association between CYP1A1 genotypes and oral cancer has been reported from various geographic regions, such as Japan (Sugimura et al., 2006), Brazil (Leichsenring et al., 2006; Marques et al., 2006; LosiGuembarovski et al., 2008), the USA (using whites) (Buch et al., 2008), and Jakarta (Amtha et al., 2009), the CYP1A1 $(\mathrm{m} 2 / \mathrm{m} 2)$ genotype did present this association with increased risk, in Koreans (Cha et al., 2007). Furthermore, gene to gene interaction studies revealed that, besides oral cancer (Anantharaman et al., 2007), GSTM1 null and CYP1A1 polymorphism increased the risk of head and neck cancers (Gattas et al., 2006).

In the present study, the prevalence of IVS1-728G > $\mathrm{A}$, and Ile462Val polymorphisms in the CYP1A1 gene in south Indian oral-cancer patients and controls, was presented. Apparently there was no association between this gene and oral cancer. Although the whole range of polymorphic genes involved in detoxification metabolism have been the base of intensive epidemiological studies over the past few years, further investigation is still called for in order to determine whether these or additional gene-gene interactions are crucial in determining the possibility of carriers of CYP1A1 alleles presenting an increased or reduced risk of cancer.

\section{Acknowledgments}

This research work was supported by an intramural grant from Sri Ramachandra University, Chennai. 


\section{References}

Amtha R, Ching CS, Zain R, Razak IA, Basuki B, Roeslan BO, Gautama W and Purwanto D (2009) GSTM1, GSTT1 and CYP1A1 polymorphisms and risk of oral cancer: A casecontrol study in Jakarta, Indonesia. Asian Pac J Cancer Prev 10:21-26.

Anantharaman D, Chaubal PM, Kannan S, Bhisey RA and Mahimkar MB (2007) Susceptibility to oral cancer by genetic polymorphisms at CYP1A1, GSTM1 and GSTT1 loci among Indians: Tobacco exposure as a risk modulator. Carcinogenesis 28:1455-1462.

Barrett JC, Fry B, Maller J and Daly MJ (2005) Haploview: Analysis and visualization of LD and haplotype maps. Bioinformatics 21:263-265.

Buch SC, Nazar-Stewart V, Weissfeld JL and Romkes M (2008) Case-control study of oral and oropharyngeal cancer in whites and genetic variation in eight metabolic enzymes. Head Neck 30:1139-1147.

Cha IH, Park JY, Chung WY, Choi MA, Kim HJ and Park KK (2007) Polymorphisms of CYP1A1 and GSTM1 genes and susceptibility to oral cancer. Yonsei Med J 48:233-239.

Chatterjee S, Chakrabarti S, Sengupta B, Poddar S, Biswas D, Sengupta S and Talukder G (2009) Prevalence of CYP1A1 and GST polymorphisms in the population of northeastern India and susceptibility of oral cancer. Oncol Res 17:397403.

Cordero K, Espinoza I, Caceres D, Roco A, Miranda C, Squicciarini V, Santander P, Lee K, Saavedra I and Quinones L (2010) Oral cancer susceptibility associated with the CYP1A1 and GSTM1 genotypes in Chilean individuals. Oncol Lett 1:549-553.

Crofts F, Taioli E, Trachman J, Cosma GN, Currie D, Toniolo P and Garte SJ (1994) Functional significance of different human CYP1A1 genotypes. Carcinogenesis 15:2961-2963.

Cubells JF, Kobayashi K, Nagatsu T, Kidd KK, Kidd JR, Calafell F, Kranzler HR, Ichinose H and Gelernter J (1997) Population genetics of a functional variant of the dopamine betahydroxylase gene (DBH). Am J Med Genet 74:374-379.

Gattas GJ, de Carvalho MB, Siraque MS, Curioni OA, Kohler P, Eluf-Neto J and Wunsch-Filho V (2006) Genetic polymorphisms of CYP1A1, CYP2E1, GSTM1, and GSTT1 associated with head and neck cancer. Head Neck 28:819-826.

Georgiadis P, Topinka J, Vlachodimitropoulos D, Stoikidou M, Gioka M, Stephanou G, Autrup H, Demopoulos NA, Katsouyanni K, Sram R, et al. (2005) Interactions between CYP1A1 polymorphisms and exposure to environmental tobacco smoke in the modulation of lymphocyte bulky DNA adducts and chromosomal aberrations. Carcinogenesis 26:93-101.

Hahn M, Hagedorn G, Kuhlisch E, Schackert HK and Eckelt U (2002) Genetic polymorphisms of drug-metabolizing enzymes and susceptibility to oral cavity cancer. Oral Oncol 38:486-490.

Hecht SS, Carmella SG, Murphy SE, Foiles PG and Chung FL (1993) Carcinogen biomarkers related to smoking and upper aerodigestive tract cancer. J Cell Biochem Suppl 17F:27-35.

Hildebrand CE, Gonzalez FJ, McBride OW and Nebert DW (1985) Assignment of the human 2,3,7,8-tetrachlorodibenzo-p-dioxin-inducible cytochrome P1-450 gene to chromosome 15. Nucleic Acids Res 13:2009-2016.
International Agency for Research on Cancer (1987) IARC Monographs on the Evaluation of Carcinogenic Risks to Humans. Supplement. Secretariat of the World Health Organization distributor, Geneva, 5 pp.

Kao SY, Wu CH, Lin SC, Yap SK, Chang CS, Wong YK, Chi LY and Liu TY (2002) Genetic polymorphism of cytochrome P4501A1 and susceptibility to oral squamous cell carcinoma and oral precancer lesions associated with smoking/betel use. J Oral Pathol Med 31:505-511.

Kristiansen W, Haugen TB, Witczak O, Andersen JM, Fossa SD and Aschim EL (2011) CYP1A1, CYP3A5 and CYP3A7 polymorphisms and testicular cancer susceptibility. Int $\mathrm{J}$ Androl 34:77-83.

Leichsenring A, Losi-Guembarovski R, Maciel ME, Losi-Guembarovski A, Oliveira BW, Ramos G, Cavalcanti TC, Bicalho MG, Cavalli IJ, Colus IM, et al. (2006) CYP1A1 and GSTP1 polymorphisms in an oral cancer case-control study. Braz J Med Biol Res 39:1569-1574.

Losi-Guembarovski R, Colus IM, De Menezes RP, Poliseli F, Chaves VN, Kuasne H, Leichsenring A, Guembarovski AL, Oliveira BW, Ramos G, et al. (2008) Lack of association among polymorphic xenobiotic-metabolizing enzyme genotypes and the occurrence and progression of oral carcinoma in a Brazilian population. Anticancer Res 28:1023-1028.

Ma Q and Lu AY (2007) CYP1A induction and human risk assessment: An evolving tale of in vitro and in vivo studies. Drug Metab Dispos 35:1009-1016.

Marques CF, Koifman S, Koifman RJ, Boffetta P, Brennan P and Hatagima A (2006) Influence of CYP1A1, CYP2E1, GSTM3 and NAT2 genetic polymorphisms in oral cancer susceptibility: Results from a case-control study in Rio de Janeiro. Oral Oncol 42:632-637.

Nakajima T, Elovaara E, Anttila S, Hirvonen A, Camus AM, Hayes JD, Ketterer B and Vainio H (1995) Expression and polymorphism of glutathione S-transferase in human lungs: Risk factors in smoking-related lung cancer. Carcinogenesis 16:707-711.

Nebert DW (1991) Role of genetics and drug metabolism in human cancer risk. Mutat Res 247:267-281.

Omiecinski CJ, Redlich CA and Costa P (1990) Induction and developmental expression of cytochrome P450IA1 messenger RNA in rat and human tissues: Detection by the polymerase chain reaction. Cancer Res 50:4315-4321.

Oude Ophuis MB, van Lieshout EM, Roelofs HM, Peters WH and Manni JJ (1998) Glutathione S-transferase M1 and T1 and cytochrome $\mathrm{P} 4501 \mathrm{~A} 1$ polymorphisms in relation to the risk for benign and malignant head and neck lesions. Cancer 82:936-943.

Park JY, Muscat JE, Ren Q, Schantz SP, Harwick RD, Stern JC, Pike V, Richie Jr JP and Lazarus P (1997) CYP1A1 and GSTM1 polymorphisms and oral cancer risk. Cancer Epidemiol Biomarkers Prev 6:791-797.

Parkin DM, Bray F, Ferlay J and Pisani P (2005) Global cancer statistics, 2002. CA Cancer J Clin 55:74-108.

Rendic S and Guengerich FP (2010) Update information on drug metabolism systems-2009, part II: Summary of information on the effects of diseases and environmental factors on human cytochrome P450 (CYP) enzymes and transporters. Curr Drug Metab 11:4-84.

Schwarz D, Kisselev P, Cascorbi I, Schunck WH and Roots I (2001) Differential metabolism of benzo[a]pyrene and ben- 
zo[a]pyrene-7,8-dihydrodiol by human CYP1A1 variants. Carcinogenesis 22:453-459.

Sikdar N, Mahmud SA, Paul RR and Roy B (2003) Polymorphism in CYP1A1 and CYP2E1 genes and susceptibility to leukoplakia in Indian tobacco users. Cancer Lett 195:33-42.

Singh N, Mitra AK, Garg VK, Agarwal A, Sharma M, Chaturvedi R and Rath SK (2007) Association of CYP1A1 polymorphisms with breast cancer in North Indian women. Oncol Res 16:587-597.

Sreelekha TT, Ramadas K, Pandey M, Thomas G, Nalinakumari KR and Pillai MR (2001) Genetic polymorphism of CYP1A1, GSTM1 and GSTT1 genes in Indian oral cancer. Oral Oncol 37:593-598.

Sugimura T, Kumimoto H, Tohnai I, Fukui T, Matsuo K, Tsurusako S, Mitsudo K, Ueda M, Tajima K and Ishizaki K (2006) Gene-environment interaction involved in oral carcinogenesis: Molecular epidemiological study for metabolic and DNA repair gene polymorphisms. J Oral Pathol Med 35:11-18.

Thangaraj K, Joshi MB, Reddy AG, Gupta NJ, Chakravarty B and Singh L (2002) CAG repeat expansion in the androgen receptor gene is not associated with male infertility in Indian populations. J Androl 23:815-818.
Tregouet DA and Garelle V (2007) A new JAVA interface implementation of THESIAS: Testing haplotype effects in association studies. Bioinformatics 23:1038-1039.

Whitlock Jr JP (1999) Induction of cytochrome P4501A1. Annu Rev Pharmacol Toxicol 39:103-125.

Wright CM, Larsen JE, Colosimo ML, Barr JJ, Chen L, McLachlan RE, Yang IA, Bowman RV and Fong KM (2010) Genetic association study of CYP1A1 polymorphisms identifies risk haplotypes in nonsmall cell lung cancer. Eur Respir J 35:152-159.

Xie H, Hou L, Shields PG, Winn DM, Gridley G, Bravo-Otero E, Diehl SR, Bowman ED, Brown LM and Hayes RB (2004) Metabolic polymorphisms, smoking, and oral cancer in Puerto Rico. Oncol Res 14:315-320.

Zhang ZY, Fasco MJ, Huang L, Guengerich FP and Kaminsky LS (1996) Characterization of purified human recombinant cytochrome P4501A1-Ile462 and -Val462: Assessment of a role for the rare allele in carcinogenesis. Cancer Res 56:3926-3933.

Zhuo W, Wang Y, Zhuo X, Zhu Y, Wang W, Zhu B, Li D and Chen Z (2009) CYP1A1 and GSTM1 polymorphisms and oral cancer risk: Association studies via evidence-based meta-analyses. Cancer Invest 27:86-95.

Associate Editor: Jeremy A. Squire

License information: This is an open-access article distributed under the terms of the Creative Commons Attribution License, which permits unrestricted use, distribution, and reproduction in any medium, provided the original work is properly cited. 